\title{
Sobre Memória, Representação e Identidade Social: alguns aspectos teóricos.
}

About Memory, Representation and Social Identity: some theoretical aspects. Acerca de Memoria, Representación e Identidad Social: algunos aspectos teóricos.

\section{Renata Patricia Forain de Valentim}

Universidade do Estado do Rio de Janeiro, Rio de Janeiro, RS, Brasil.

\section{Zeide Araújo Trindade}

Universidade do Estado do Rio de Janeiro, Rio de Janeiro, RJ, Brasil.

\section{Resumo}

Neste trabalho alguns aspectos teóricos relativos ao conceito de Memória Social serão discutidos e alinhavados à teoria das Representações Sociais e à teoria da Identidade Social, em particular aqueles que rompem com a idéia da memória como um depósito de traços do passado e que permitem compreender as representações mnêmicas de modo dinâmico, como reconstruções fundadas dialeticamente em relação às inúmeras necessidades do presente. Nesta perspectiva, o necessário reconhecimento de uma pluralidade de tempos, o assentimento da multiplicidade de versões acerca das histórias que cada grupo seleciona, institucionaliza e transmite através da interação de seus membros, bem como a idéia da identidade social como um processo a ser definido sempre à posteriori, nas novas significações que vão sendo atribuídas à realidade pelos grupos ao longo de sua história.

Palavras-chave: Memória social, Representação social, Identidade social.

\section{Resumen}

En este trabajo se discutirá algunos aspectos teóricos sobre el concepto de la memoria social relacionándolos a la teoría de las representaciones sociales y la teoría de la identidad social, en particular aquellos que rompen con la idea de la memoria como un repositorio de huellas del pasado, comprendiendo lo que permite que permiten las representaciones mnémicas de forma dinámica, dialéctica, basada en la reconstrucción y en comparación con las necesidades del presente. En esta perspectiva, el necesario reconocimiento de una pluralidad de tiempos, el consentimiento de la multiplicidad de versiones sobre las historias que cada grupo elige, institucionaliza y se transmite a través de la interacción de sus miembros, así como la idea de la identidad social como un proceso para establecer cada uno posteriormente, los nuevos 
significados que los grupos atribuyen a lo largo de su historia.

Palabras clave: Memoria social, Representación social, Identidad social.

\begin{abstract}
In this paper some theoretical aspects concerning the concept of social memory will be discussed and related to the theory of social representations and social identity theory, in particular those who break with the idea of memory as a repository of traces of the past and understand the mnemonic representations on their face dynamical, dialectical, based on the many needs of the present. In this perspective, the necessary recognition of a plurality of times, the consent of the multiplicity of versions about the stories that each group selects, institutionalizes and transmits through the interaction of its members, as well as the idea of social identity as a process to be set each subsequently, the new meanings that are being attributed to the fact the groups throughout its history.
\end{abstract}

Keywords: Social memory, Social representation, Social identity.

\title{
Introdução
}

Não é recente o interesse que cerca os relatos da memória. No campo literário, de Proust e Joyce a Machado de Assis e Borges, passando por autores tão diferentes quanto Sartre ou Nelson Rodrigues é possível identificar uma extensa produção literária de cunho memorialista. Ou ainda nas diversas correntes filosóficas e científicas que, de Platão a Bergson, Halbwachs ou Bartlett pretendem dar conta desta "região da experiência coletiva e individual" (Duvignaud, 2008, p. 9) constituída pelas reminiscências.

Será, entretanto, entre o final do século XIX e princípio do século XX, na especificidade do contexto econômico, social e cultural engendrado pela modernidade e suas revoluções econômicas, políticas e religiosas, que a questão da memória vai se fixar como um tema central. Seja para a literatura, para a psicologia ou as ciências sociais, este deslocamento será comumente identificado à experiência histórica inédita de transposição dos fundamentos e práticas que abasteciam as sociedades rurais, tradicionais e comunitárias em direção a uma composição técnica, urbana e industrializada (Jedlowski, 2005; Namer, 1994).

Neste trabalho serão analisados alguns aspectos do conceito de Memória Social, alinhavando-os à teoria das 
Representações Sociais e à teoria da Identidade Social (Tajfel, 1981), especialmente a partir da premissa que posiciona o passado como reconstrução, fundado dialeticamente em função das inúmeras necessidades do presente. $\mathrm{Na}$ análise desta reconstrução, que se estabelece não como originária mas sim como "verossímil" (Bonardi, 2005), um duplo retorno: em primeiro lugar ao contexto de sua enunciação e à eficácia social desta dinâmica para a manutenção do grupo e para sua homeostase. Em segundo, ao papel que esta transmissibilidade exerce nas formas de atualização destes conteúdos e a importância desta atualização para a construção da identidade social do grupo.

O objetivo maior, neste caso, é referendar a posição do conceito de memória social no âmbito de uma perspectiva psicossocial, como categoria organizadora de experiências e percepção, que ilumina esta capacidade de contínua reorganização da atividade representacional e ajuda a compreender o "hibridismo" (Bhabha, 2001; Hall, 2006) de sua composição. Montagem seletiva, que associa as crenças estáveis e estabelecidas há muito pelas comunidades às mais modernas formas de nomeação e de recursos tecnológicos em um mesmo discurso, e que se utiliza da reorganização dos traços mnêmicos para uma resignificação da realidade.

Considera-se assim que o marco zero da relação entre a memória e a cultura ocidental, moderna e "europeizada" pode ser situado no contexto destas transformações.

Aparecimento significativamente localizado no esteio das mudanças que causam e são causadas pela primeira grande guerra mundial e pela universalização do modelo dos "EstadosNação" (Elias, 1995); pela crescente urbanização da população e estatização dos sistemas de saúde e educação; pela industrialização das cidades e o progresso da técnica e do pensamento científico em detrimento das práticas e dos conhecimentos tradicionais (Souza, 2005).

Sob o peso destas novas circunstâncias e do necessário estabelecimento de categorias e conceitos para sua formulação (Namer, 1994), o estudo da memória é marcado, no alvorecer do século $\mathrm{XX}$, pelas obras seminais de Halbwachs e Bartlett, que introduzem ao menos duas variações no estudo da reminiscência. $\mathrm{Na}$ primeira, a consideração dos contextos sociais reais de tempo e espaço que servem de baliza à reconstrução de cada lembrança individual (Duvignaud, 2006); o contexto de referência no qual atualmente transitam o grupo e o indivíduo que o atesta; bem como os mecanismos psicossociais que 
permitirão, no interior destes contextos, o trânsito entre os elementos socialmente mais estabilizados e aqueles que surgem como forças exógenas, externas ao grupo (Bartlett, 1932/ 1995).

$\mathrm{Na}$ segunda, o reconhecimento de uma "pluralidade de tempos" ligada principalmente às múltiplas versões - agora socialmente contextualizadas e desligadas de sua condição de convenção matemáticade um grupo sobre seu passado; que podem e devem ser consideradas como legítimas, ainda que diluídas em meio à multiplicidade de outras formas culturais e sociais de marcação temporal (Viaud, 2002). Ou, de forma ainda mais radical, mesmo que diluídas entre lembranças "verídicas" e outras, que sejam recontadas e selecionadas como um "ato social" (Kintsch, 1995).

Ainda no século vinte, em suas últimas duas ou três décadas, pode ser verificada uma efetiva retomada nos estudos da memória em seus termos sociais, seja na sociologia, na história ou na antropologia, “às quais, não muito tempo depois veio se associar a psicologia social.” (Sá, 2005, p. 63). Considerado como uma "epistemologia dinâmica" (Valencia, 2005, p. 102); como lugar teórico multifacetado e complexo (Viaud, 2003); ou “diversificado” (Sá, 2005, p. 63), o estudo das representações mnêmicas sob a perspectiva psicossocial guarda, não obstante, como um de seus traços fundamentais e comuns, o fato de não conceber o campo da memória a partir do modelo de um "depósito" de traços do passado (Jedlowski, 2001), pertencente ao “domínio individual e à sua explicação em termos estritamente psicológicos" (Sá, 2005, p. 63). A memória social é tomada aqui como o lugar "da pluralidade de funções inter-relacionadas" (Jedlowski, 2005 , p. 30), definida como "um conjunto de representações relativas ao passado que cada grupo produz, institucionaliza, cuida e transmite por meio da interação de seus membros" (Jedlowski, 2005, p.31); ou como o conjunto de representações do passado, majoritariamente partilhadas, resultado de uma série de práticas seletivas, exercidas de maneira explícita ou implícita. (Vidal-Beneyto, 2003).

Sob esta nova perspectiva os traços mnêmicos são dinâmicos, devendo ser interpretados segundo as vicissitudes e necessidades do presente, em uma complexa dialética temporal. Por um lado, os acontecimentos passados que acarretam as condições posteriores da interpretação e do reconhecimento; de outro, o presente que modela o passado, ordenando, reconstruindo e interpretando seu legado, com expectativas e esperanças que ajudam a selecionar dentre essas lembranças as que mais servem a um determinado futuro. 
Para Jedlowski (2001) ou Sá (2007), nesta proposição conceitual estaria a principal influência unificadora do campo, fazendo demarcar seu domínio epistêmico frente às "perspectivas psicologicistas segundo as quais as experiências permanecem intactas na memória dos indivíduos, podendo ser, com maior ou menor dificuldade, por eles reproduzidas" (Sá, 2007, p. 2). Nas palavras de Jedlowski (2001):

O que chamamos memória é uma complexa rede de atividades, seu estudo indica que $\mathrm{o}$ passado nunca retorna $\mathrm{o}$ mesmo, mas é constantemente selecionado, filtrado e reestruturado nos termos das questões e necessidades do presente nos níveis sociais e individuais. (p.30)

Nesta reprodução reside a capacidade da memória social em "reinventar a tradição" (Jedlowski, 2001, p. 35); bem como sua "eficácia social" (Viaud, 2002, p. 22) e seu poder de coesão e legitimação para um determinado grupo. Segundo Viaud (2002):

(A memória social é) produto de um saber compartilhado pelos grupos sociais e do qual o efeito de verdade produzido - sua eficácia social - é realizado pela introdução de um nível simbólico dentro do discurso sobre o passado e pela legitimação deste discurso para as instâncias externas ao grupo. (p. 22) $)^{1}$

Este "nível simbólico dentro do discurso" poderia ser definido como a relação arbitrária ou convencional que se estabelece entre o signo e a coisa a que ele designa, onde a arbitrariedade da relação é sustentada pelas formas de representação psíquica que lhe emprestam significação (Barthes, 2007; Pignatari, 1971). Sua admissão funciona como condição de entendimento da categoria de memória social na medida em que ela torna a relação entre a representação e o representado uma composição seletiva, desnaturalizada, majoritariamente partilhada e obediente a critérios históricos, culturais ou sociais particulares ao grupo: "é a linguagem, e é todo o sistema de convenções sociais que lhes são solidárias, que nos permitem a cada instante reconstruir nosso passado". (Halbwachs, 1925/ 1994, p. 279)

Estes critérios, impostos coletivamente às memórias individuais, organizam-se em torno de um eixo determinado, que lhes confere uma direção e lhes permite funcionar como base de uma determinada comunidade. (Vidal-Beneyto, 2003). Este eixo, desenvolvido singularmente por cada cultura, não é necessariamente lógico, linear ou racional (Valencia, 2005). Embora fundado a partir 
de uma "structure of cohesion" (Brockmeier, 2002, p. 18), o trabalho da memória, por estar obediente às circunstâncias contemporâneas de sua enunciação, junta às vezes "informações estranhas do passado de maneira imprevisível" (Valencia, 2005, p. 105).

As questões que rondam as relações entre $\mathrm{o}$ passado e $\mathrm{o}$ presente $\mathrm{e}$ a necessidade de reorganizar permanentemente as representações sedimentadas em diferentes tempos levaram Bartlett a teorizar, já em 1932, sobre o processo de Convencionalização. Segundo o autor, partindo do princípio que o maior estímulo para as mudanças sociais vem de fora dos grupos, um grande número de métodos necessita ser definido pelo grupo a fim de que o contato com estas fontes de estimulação exógena seja, ao mesmo tempo em que franco e aberto, seletivo o suficiente para manter as marcas distintivas deste grupo. Algumas questões que Bartlett então propõe são: como e por quais mecanismos estas novas formas são incorporadas? Como seu sentido é transmitido e por quais mudanças elas devem passar para serem assimiladas pelo grupo?

Neste ponto se torna inevitável trazer à tona a relação que se constitui entre o conceito de Memória Social e a teoria das Representações Sociais. Circunscritas como forma de conhecimento prático, exercido pelo sensocomum, as Representações Sociais têm como função primordial dar forma à novidade e torná-la acessível através de uma construção comum a um dado conjunto social (Moscovici, 2004). Suas propriedades mais relevantes poderiam ser assim resumidas: 1) são socialmente elaboradas e partilhadas; 2) estabelecem uma visão de realidade comum a um grupo social (Roussiau \& Renard, 2003); 3) fornecem diretrizes práticas de organização e de comunicação nos assuntos ou temas que, nas relações cotidianas e diárias, prendem a atenção das pessoas, demandam sua compreensão e forçam seus pronunciamentos" (Sá, 1998, p.25).

Os princípios constitutivos destas representações, denominados por Moscovici de Ancoramento e Objetivação, serão responsáveis por esta transformação do desconhecido em algo "tangível", em uma linha de análise semelhante à Bartlett. Processo instituído de tal modo que a inclusão da novidade é sempre tributária de organizações semânticas anteriores, integrada de forma paulatina ao corpo de categorizações pré-existentes na medida em que lhe é atribuído um valor, uma classificação ou um nome (Licata, 2003).

Neste ponto, as semelhanças entre Memória e Representação Social aparentam sofrer uma restrição. Como conciliar as duas versões, aparentemente 
contraditórias da dinâmica e dos princípios de funcionamento psicossocial destas duas formas de registro representacional? Se na memória, os acontecimentos passados são relativizados em relação às circunstâncias atuais, nas representações sociais a dinâmica seria justamente oposta e a memória funcionaria como o fundamento intragrupal de transmissão dos elementos estáveis, auxiliando o grupo a moldar as novas aquisições, como "fundo" de conhecimentos e atitudes acerca de um objeto e referência na "constituição de uma imagem social, uma antecipação da natureza e da estrutura das imagens sociais". (Roussiau \& Bonardi, 2002, p.35).

A vinculação entre memória e representação social e suas naturais contradições e/ou revisões teóricas é um ponto que vêm sido trabalhado nos últimos anos por autores - como Bonardi (2005); Roussiau \& Renard (2003); Viaud (2003) e, no Brasil, de forma pioneira por Sá (2005, 2007) -, que destacam alguns modelos explicativos para esta relação. Em comum, a necessidade de acertar um padrão, uma estrutura ou um funcionamento sistêmico que aja em dois planos distintos: na capacidade de selecionar e manter informações acerca de um objeto, de modo que se estabeleça a coerência e a lógica de um núcleo figurativo (Bonardi 2005), bem como na possibilidade (e na necessidade) do estabelecimento contínuo de novas semânticas para estas informações e novos códigos de significação para os mesmos objetos.

Para Roussiau e Renard (2003), esta questão estaria no âmago das discussões acerca do Metasistema (em Doise e na escola de Genebra) e da Teoria do Núcleo Central (em Abric, Flament, Guimelli). Para Viaud (2002), nas questões promovidas por Moscovici acerca do conceito de Themata. Em comum, três preocupações: 1) testar a hipótese de uma disposição formadora e normativa anterior aos princípios de ancoragem e objetivação; 2) a necessidade de precisar as fronteiras entre elementos constitutivos e nãoconstitutivos das representações sociais; e 3) definir o lugar que ocupa o contexto histórico e social na formação dessa representação. (Doise, 2002)

Para Doise e a escola de Genebra esta predisposição é Metasistêmica. Atua como uma dinâmica de regulações formadoras, que controlam, verificam e dirigem as operações cognitivas via os princípios organizativos de ancoramento e objetivação. Segundo Roussiau e Renard (2003), um "Metasistema" essencialmente normativo, estabilizador destes princípios, que os faz resultado de um processo sóciohistórico comum, que regula as produções 
concretas ou simbólicas segundo a história do grupo, seus mitos, crenças e símbolos.

$\mathrm{Na}$ teoria do Núcleo Central das Representações Sociais esta predisposição se dá no modelo de uma estrutura hierarquizada, que também comporta dois sistemas: um sistema central, constituído por um ou mais elementos estáveis, coerentes e consensuais, que ocupam uma posição nuclear e privilegiada de significação; sem eles a representação se desestrutura ou adquire uma significação inteiramente diferente. E outro sistema, periférico, flexível, adaptativo e relativamente heterogêneo em relação ao seu conteúdo (Sá, 2002), que surge como índice das transformações que atravessam as formas de representar determinado objeto ao longo do tempo.

No conceito de Themata, a disposição que antecede, estrutura ou dirige os princípios de ancoragem e objetivação também é percebida como a tentativa de conciliar a tensão entre uma herança representacional e as situações transformadoras: "a oposição tradicional entre a permanência dos arquétipos e aquela diversidade expressa pelas representações, entre continuidade e descontinuidade, entre a longa duração e o “acontecimento"” (Viaud, 2003, p. 17). Para tanto, a análise temática se concentra na identificação dos "thêmata canoniques" e na emergência das significações que se estabelecem e "em redor dos quais as representações são formadas”. (Moscovici, 2004):

\begin{abstract}
A análise das representações sociais não pode fazer mais que tentar, por um lado, identificar o que, em determinado nível axiomático em textos e opiniões, chega a operar como "primeiros princípios", "idéias propulsoras" ou "imagens". (p. 242)
\end{abstract}

Segundo Moscovici (2004), a análise temática das representações comportaria então a identificação destes "lugares primários". Sintaxe que rege as relações internas do discurso ao mesmo tempo em que estabelece as leis gerais de organização das construções mentais, definindo um lugar semântico, não o conteúdo que o ocupa: "Eles tomam a forma de "noções", isto é, de "locais potenciais de significação como geradores de concepções" (Moscovici, 2004, p. 243), cujo sentido só se realiza plenamente no interior de um discurso mais complexo, onde interagem múltiplas variáveis individuais e coletivas.

Decorre assim, que o sentido pleno de uma representação não pode ser tomado como um princípio que se realize em si mesmo, de forma imediata. O sentido, neste caso, se dá muito mais como um fim temporário, que só pode se realizar a 
posteriori, como uma tendência, que pode ou não ser corroborada:

(...) toda representação social é constituída como um processo em que se pode localizar uma origem, mas uma origem que é sempre inacabada, a tal ponto que outros fatos ou discursos virão nutri-la ou corrompê-la (p. 218).

Ainda segundo Moscovici (2004), esta tendência precisa ser compreendida de modo contextualizado, como um fenômeno de coesão sociodiscursiva, que obedece a princípios singulares de coerência estrutural. Princípios não arbitrários, que constituem e são constituídos na lógica de uma relação interna-externa, familiarestranho, e que abrangem desde esquemas cognitivos, atitudes e posicionamentos até modelos culturais e normas.

\section{Considerações Finais}

Ressurge assim a questão sobre o papel da memória e de seu lugar no arranjo destas leis estruturantes de significação, tanto do plano individual e do desenvolvimento dos mecanismos cognitivos, como do plano social e da estruturação do discurso comum que unifica o grupo. Onde ela pode ser melhor identificada? No núcleo primário, estruturante e estabilizado da representação? Ou, ao contrário, nas marcas mais volúveis e nas franjas periféricas que guardam, em sua sucessão, a lógica e a historicidade grupal de seu uso e desuso? Qual a relação entre a memória e estes princípios que regem a dimensão identitária do interno e do externo, do familiar e do estranho?

Estas questões - algumas dentre muitas que poderiam ser levantadas -, fazem parte de uma diretriz propositalmente dada a este trabalho: a organização de uma rede conceitual ampla, que fixasse os parâmetros de investigação e de interpretação dos dados a partir do entrelaçamento de categorias e conceitos "irmãos". Seu estabelecimento veio como uma necessidade progressiva, dada ao longo dos estudos, realimentada pelo que ia sendo observado no campo e por tudo aquilo que não possuía uma chave interpretativa imediata.

Desse modo, verifica-se que as categorias e teorias propostas, apesar de qualitativamente diferentes, têm como objetivo comum uma análise que poderia ser definida como "societal" (Doise, 2002), que articula tanto o domínio individual de processos que permitem funcionar em sociedade, quanto, de forma complementar, as "dinâmicas sociais, particularmente interacionais, posicionais ou de valores e de crenças gerais, orientam o funcionamento desses processos" (Doise, 2002, p. 28). Ou seja, o liame entre as 
características individuais e as coletivas e o limite entre o que é inter e intra grupal ou mesmo no que é culturalmente endógeno ou exógeno.

Além do conceito de memória social e da teoria das representações sociais, preenche ainda este contexto a Teoria da Identidade Social, conforme proposta por Tajfel. De base psicossocial, através dela a identidade é definida como mutável e flexível e onde a atividade de "reconstrução semântica" (De Rosa \& Mormino, 2002, p. 120) é ininterrupta e intimamente ligada à idéia de pertença e ao significado avaliativo que dela resulta (Tajfel, 1981).

Nesta pertença, a filiação grupal acorre de forma concomitante ao desenvolvimento de processos cognitivos e emocionais, formadores da idéia de alteridade e da percepção do lugar que o indivíduo ocupa na sociedade. Segundo Cabecinhas (2006), são estratégias que não apenas definem as relações do indivíduo no interior do grupo, como também as relações com os outros grupos; "numa dinâmica onde, conforme o momento histórico, pode prevalecer a estabilidade ou a mudança, a resistência ou a adaptação, a preservação das fronteiras, a sua diluição ou a demarcação de novas”. (p. 67)

A dinâmica da identidade social acorre precisamente neste gradiente do in group e do out group, atuando em resposta às dinâmicas sociais (Suda \& Souza, 2006) e às interações intergrupais construídas ao longo de sua história; estabelecendo, a seu modo, os mesmos questionamentos que rondam a constituição das representações e memórias sociais e dos processos psicossociais aí envolvidos.

$\mathrm{O}$ recurso à teoria da Identidade Social trabalha ainda em um outro plano, que permite relacionar memória e representação às formas propositivas, futuras, que vão se desenhando no interior do grupo. Pensando a identidade como um processo definido sempre à posteriori - a partir das ininterruptas demandas de convencionalização, estabilização e transmissão de novos conteúdos - é possível sempre percorrer o sentido inverso deste processo, recolocar o problema das atribuições de sentido e buscar nas novas significações, os traços passados que foram eleitos para permanecer através das multiplas narrativas e serem relançados como um tributo às futuras gerações.

\section{Notas}

1 Todas as traduções são nossas.

\section{Referências}

Barthes, R. (2007). Elementos de Semiologia. Lisboa: Ed 70.

Bartlett, F.C. (1995). Remembering. A study in experimental and social 
psychology. Cambridge: University

Press. (Originalmente publicado em 1932).

Bonardi, C. (2005). Représentations sociales e mémoire: de la dynamique aux structures premières. Connexions, 84, 43-57.

Brockmeier, J. (2002). Remembering and forgetting: narrative as cultural memory. Culture and Psychology, 8 (1), 15-43.

Cabecinhas, R.; Lima, M.E.O. \& Chaves, A.M. (2006) Identidades nacionais e memória social: hegemonia e polémica nas representações sociais da história. In Miranda, J. \& João, M. I. (Eds.) (2006) Identidades Nacionais em Debate, Oeiras: Celta, 67-92.

De Rosa, A.S.; Mormino, C. (2002) Au confluent de la mémoire sociale: étude sur l'identité nationale et européenne. In: LAURENS, S.; ROUSSIAU, N. (Orgs.). La mémoire sociale: identités et représentations sociales. Rennes: PUR.

Doise, W. (2002). Da psicologia social à psicologia societal. Psicologia: Teoria e Pesquisa, 18(1), 27-35.

Duvignaud, J. (2006). Prefácio. In Halbwachs, M. (2006) A memória Coletiva. (pp 7-16). SP: Centauro.
Halbwachs, M. (1994). Les cadres sociaux de la mémoire. Paris: Albin Michel. (Originalmente publicado em 1925).

Jedlowski, P. (2001). Memory and sociology: Themes and issues. Time \& Society, 10(1), 29-44.

Jedlowski, P. (2005). Representações sociais e memória social: vicissitudes de um objeto em busca de uma teoria. In C. P. de Sá (Org.), Memória, imaginário e representações sociais (pp. 99-120). Rio de Janeiro: Museu da República. Kintsch (1995). Introduction. In Bartlett, F. C. Remembering. A study in experimental and social psychology. Cambridge: University Press. (Originalmente publicado em 1932).

Licata, L. (2003). Representing the Future of the European Union: consequences on national and European identification. Papers on Social Representations v.12, 5.15.22 .

Moscovici, S. (2004) Representações Sociais. Petrópolis: Vozes.

Namer, G. (1994). Postface. In Halbwachs, M. (1925/ 1994) Les cadres sociaux de la mémoire. (pp. 297-367). Paris: Albin Michel.

Pignatari, D. (1971). Informação, linguagem, comunicação. SP: Perspectiva. 
Roussiau, N. \& Bonardi, C. (2002). Quelle place occupe la mémoire sociale dans le champ des représentations sociales. In S. Laurens \& N. Roussiau (Orgs.), La mémoire sociale. Identités et représentations sociales (pp. 33- 49). Toulouse: PUR.

Roussiau, N. \& Renard, E. (2003). Des representations sociales a l'instituonnalisation de la mémoire sociale. Connexions, 80, 31-41.

Sá, C. P. De (1998). A construção do Objeto de Pesquisa em Representações Sociais. RJ : EDUERJ.

Sá, C. P. de (2002). O núcleo central das representações sociais. R.J : Vozes.

Sá, C. P. de. (2005). As memórias da memória social. In C. P. de Sá (Org.), Memória, imaginário e representações sociais (pp. 63-86). Rio de Janeiro: Museu da República.

Sá, C. P. (2007). Sobre o campo de estudo da memória social: uma perspectiva psicossocial. Psicologia, Reflexão e Crítica, 20, 290-295.

Santos. B. S.; Meneses, M. P. G \& Nunes, J. A. (2005) Introdução: Para ampliar o cânone da ciência: a diversidade epistemológica do mundo. In B. S. Santos (org) Semear outras soluções. Os caminhos da biodiversidade e dos conhecimentos rivais (pp. 21-25). R.J.: Civilização Brasileira.

Suda, J. \& Souza, L. (2006). Identidade social em movimento: a comunidade japonesa na Grande Vitória (ES). Psicologia e Sociedade, 18 (2), 7280.

Tajfel, H. (1981) Grupos Humanos $e$ Categorias Sociais, v. 1 e 2. Lisboa: Livros Horizonte.

Valencia, P. (2005). Representações sociais e memória social: vicissitudes de um objeto em busca de uma teoria. In C. P. de Sá (Org.), Memória, imaginário $e$ representações sociais (pp. 99-120). Rio de Janeiro: Museu da República. Viaud, J. (2002). Contribution à l'actualisation de la notion de mémoire collective. In S. Laurens \& N. Roussiau (Orgs.), La mémoire sociale. Identités et représentations sociales (pp. 21-32). Toulouse: PUR.

Viaud, J. (2003). Mémoire collective, représentations sociales et pratiques sociales. Connexions, 80, 13-30.

Vidal-Beneyto, J. (2003). La construction de la mémoire collective. Du franquisme à la démocratie. Diogène, 201, 17-28.

\section{Renata Patricia Forain de Valentim Graduada em Psicologia pela UFRJ,}


mestre em Estudos Literários pela UFES e doutora em Psicologia também pela UFES. Atualmente é professora colaboradora do Programa de Pós Graduação em Psicologia Social da UERJ.

E-mail: renatapfvalentim@gmail.com

Zeide Araújo Trindade é doutora em psicologia e professora titular do Programa de Pós Graduação em Psicologia da Universidade do Estado do Espírito Santo. E-mail: zeidi@uol.com.br 